This item was submitted to Loughborough's Research Repository by the author.

Items in Figshare are protected by copyright, with all rights reserved, unless otherwise indicated.

\title{
Quantifying part irregularities and subsequent morphology manipulation in stereolithography plastic injection moulding
}

PLEASE CITE THE PUBLISHED VERSION

PUBLISHER

(C) Maney Publishing

VERSION

VoR (Version of Record)

LICENCE

CC BY-NC-ND 4.0

\section{REPOSITORY RECORD}

Harris, Russell A., Farid Fouchal, Richard J.M. Hague, and Phill M. Dickens. 2019. "Quantifying Part Irregularities and Subsequent Morphology Manipulation in Stereolithography Plastic Injection Moulding". figshare. https://hdl.handle.net/2134/4651. 
This item was submitted to Loughborough's Institutional Repository (https://dspace.lboro.ac.uk/) by the author and is made available under the following Creative Commons Licence conditions.

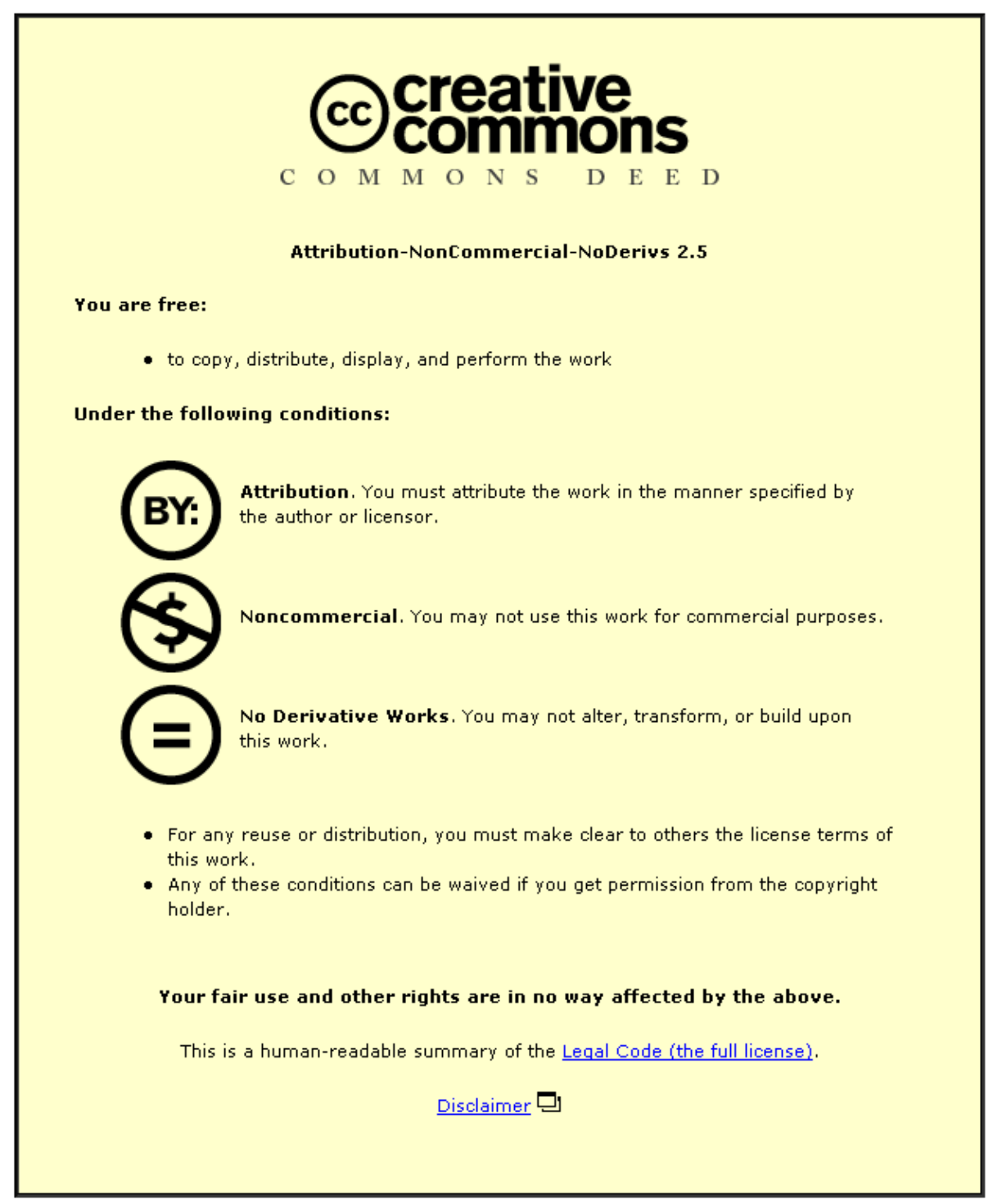

For the full text of this licence, please go to: http://creativecommons.org/licenses/by-nc-nd/2.5/ 


\title{
Quantifying part irregularities and subsequent morphology manipulation in stereolithography plastic injection moulding
}

\author{
R. A. Harris ${ }^{* 1}$, F. Fouchal ${ }^{1}$, R. J. M. Hague ${ }^{1}$ and P. M. Dickens ${ }^{1}$
}

The direct use of moulds produced by stereolithography (SL) provides a rapid tooling technique which allows low volume production by plastic injection moulding. The greatest advantage of the process is that it provides parts that are the same as those that would be produced by metal tooling in a fraction of the time and cost. However, work by the authors demonstrates that the parts possess different characteristics to those produced by metal tooling. This knowledge defies the greatest advantages of the SL injection moulding tooling process - the moulded parts do not replicate parts that would be produced by metal tooling. This work specifically demonstrates that a different rate of part shrinkage is experienced and subsequently investigates the mechanisms in $S L$ tooling that induce these different part properties. The work culminates in different approaches to modifying the moulding process which allow the production of parts whose key morphological characteristics are closer to those that have been produced from metal moulds.

Keywords: Rapid prototyping, Stereolithography, Plastic injection moulding, Crystallinity

PRC/2072

\section{Background}

\section{Stereolithography tooling for plastic injection moulding}

Rapid Prototyping (RP) allows physical models of parts to be realised very early in the design and development phase. However, the requirements of such models have now progressed beyond the alpha development phase (validation of design concepts) and onto the beta phase (physical testing and in-practice application of the parts). For such tests to be conducted, the part must be produced in the material and by the process intended for the production intent part. For injection moulded parts, this situation highlights the requirement of a rapid mould making system that can deliver these parts within the time and cost boundaries.

Stereolithography (SL) is an RP technique that allows for rapid, direct generation of epoxy and/or acrylic tooling inserts that can be used in injection moulding. The accuracy of the SL RP process results in inserts that require few further operations before their use in injection moulding. Thus, the process provides a quick route to tooling that, depending on geometric complexity and the moulding polymer, can produce $\geqslant 50$ parts. ${ }^{1}$ The supposed great advantage of the process is that it provides a low volume of parts that are identical to parts that would be produced by metal tooling in a fraction of the time and cost.

${ }^{1}$ Rapid Manufacturing Research Group, Loughborough University, Loughborough, UK

*Corresponding author, email R.A.Harris@lboro.ac.uk
The key to successful SL tooling is to understand the demands of the mould design and injection moulding parameters, which are very different from those for metal moulds. It has been demonstrated that appropriate choices in mould design and process variables can reduce the risk of failure in SL tooling. ${ }^{2-4}$ Various polymers have been successfully moulded by SL injection moulding. These include polyester (PE), polypropylene (PP), polystyrene (PS), polyamide (PA), polycarbonate (PC), polyether-ether-ketone (PEEK), acrylonitrile-styrene-acrylate (ASA) and acrylonitrilebutadiene-styrene (ABS). ${ }^{5-8}$

\section{Moulded parts characteristics}

Several authors have indicated differences in the mechanical properties of parts produced by SL moulds compared to those from metal moulds. ${ }^{6,8-11}$

These findings compromise the greatest advantages of the SL injection moulding tooling process; the moulded parts do not replicate parts that would be produced by metal tooling. The hypothesis of this work was to quantify one aspect of part irregularities from SL tooling, subsequently to acquire an understanding of the mechanisms in SL tooling that induce these different part properties by way of morphological analysis, and consequently develop a modification of the process that would enable critical morphology manipulation which would allow the moulded parts to demonstrate characteristics like those produced by metal moulds. Should this be possible, SL tooling would be able to provide a truly comparative rapid tooling alternative for low volumes of plastic injection moulded parts. This work 

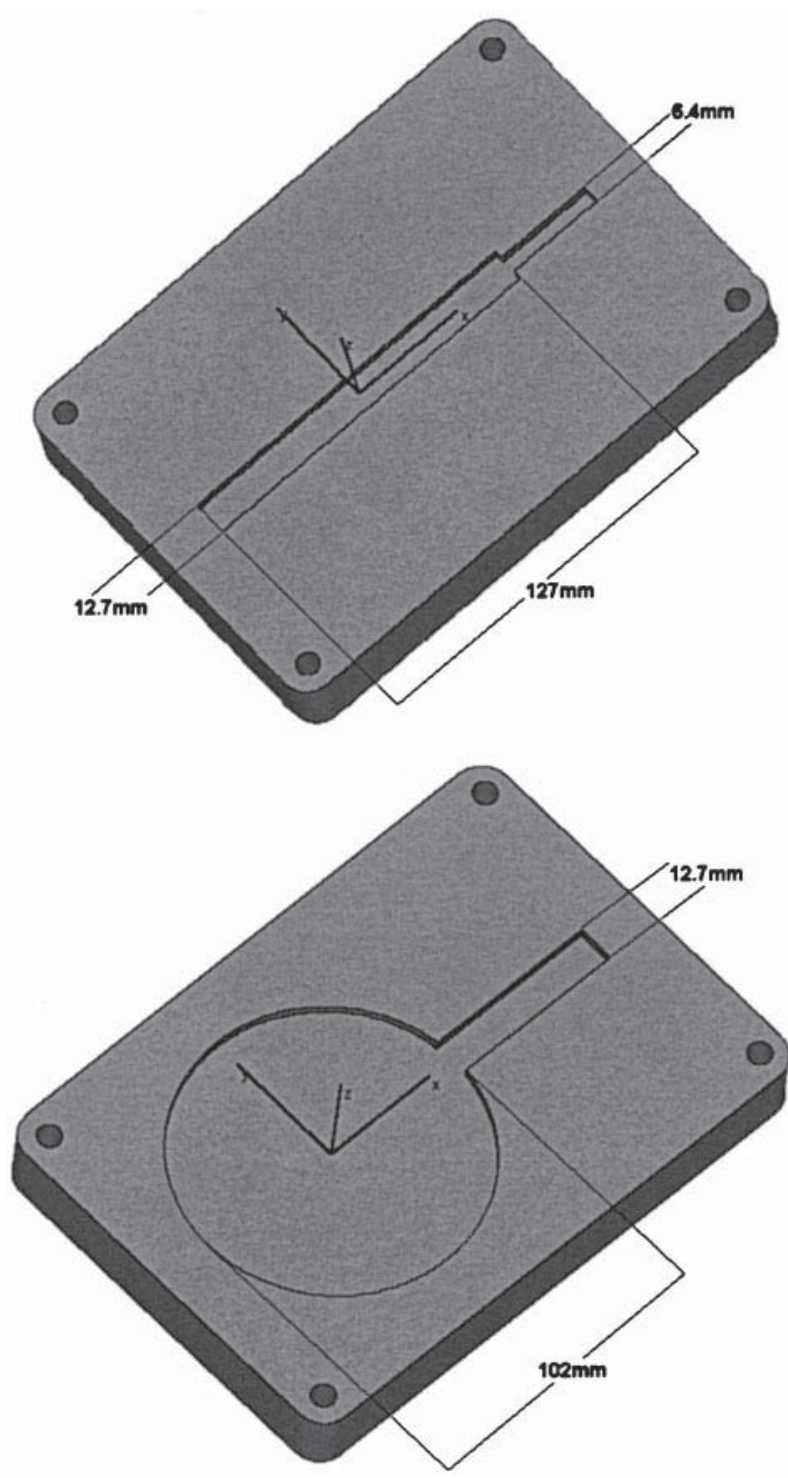

1 CAD images of bar and disc cavities

is detailed in this paper in three parts. Part 1 quantifies an aspect of part irregularities from SL moulds, Part 2 covers the identification of the cause of part anomalies, Part 3 describes the approaches taken for morphology control.

\section{Research methodology - Part 1}

The parts from SL moulds were to be compared to those from a metal mould in respect to the amount of shrinkage incurred. This attribute was chosen for study as it is an aspect to which a part's validity is particularly vulnerable. Certain aspects of anomaly can be tolerated, but size differences rarely can. Experiments were conducted to establish the shrinkage that occurs within $48 \mathrm{~h}$ of the moulding of two polymers of very different characteristics [Polyamide 66 (PA66, crystalline) and Acrylonitrile-Butadiene-Styrene (ABS, amorphous)] when produced by injection moulding in cavities of differing materials [Stereolithography (SL) and Aluminium (AL)]. This would be by a direct comparison of the dimensions of the moulding cavity and the moulded parts.

\section{Tool design}

The part and mould design was based upon an amalgamation of BS EN ISO 294-1 and $4^{12,13}$ and ASTM D955 ${ }^{14}$ standards for establishing shrinkage of injection moulded polymers. The BS standards provide great detail for the whole process but the gating arrangements specified for the testpieces are unsuited to SL injection mould tooling. SL tooling would be unable to withstand the heat and pressure in such a gating system as a result of its low strength compared to the traditional metal tooling materials. The cavity arrangement in the ASTM standard was feasible but it lacks the depth of process details contained in the BS standard. Therefore the methodology used to evaluate the total part shrinkage was based upon an amalgamation of these two standards.

Specimens of two differing geometries were moulded in order to provide shrinkage measurements both parallel (bar shape) and perpendicular (disc shape) to the direction of polymer flow. For shrinkage parallel to flow, a bar shaped cavity was used with dimensions 12.7 by $127 \mathrm{~mm}$, with a wall thickness of $3.2 \mathrm{~mm}$. This cavity was gated at one end, measuring $6.4 \mathrm{~mm}$ in width and $3.2 \mathrm{~mm}$ in depth. For diametric shrinkage, where shrinkage was measured in the opposite direction to flow, the mould consisted of a disc shaped cavity $102 \mathrm{~mm}$ in diameter by $3.2 \mathrm{~mm}$ in thickness with a gate, placed radially at the edge, $12.7 \mathrm{~mm}$ in width by $3.2 \mathrm{~mm}$ in depth. Dimensioned images of these mould cavities can be viewed in Fig. 1. The moulds did not include a part ejection system as the parts were easily removed by hand.

The SL moulds were manufactured by a 3D Systems SLA350 machine, using Vantico 5190 (epoxy) resin. The build layer thickness of the SL moulds was $0.05 \mathrm{~mm}$, as this has previously been demonstrated as an optimal value in extending the working life of SL moulds. ${ }^{15}$ The draft angle used to ease part removal from both mould varieties was $1.5^{\circ}$. This value has previously been shown to be an optimum value for reducing potential damage to SL tools upon part ejection. ${ }^{16}$ The metal moulds were machined from aluminium. Aluminium (AL) was selected as a suitable metal tooling material for comparison as it represents a closely competing commercial tooling technique since it can be quickly manufactured owing to the high cutting speeds and feedrates possible.

The inserts were contained within a steel bolster for moulding. These bolsters facilitated alignment on the machine platen, provided material entry into the mould via a tapered sprue bush and protected the inserts from any excessive application of pressure.

\section{Process parameters}

Conventionally, different injection moulding parameters would be utilised by SL and AL moulds, i.e. speeds, temperatures and pressures. However, in order to solely assess the effects of the differing mould materials on part shrinkage, it was important in this work to ensure that other influential variables were isolated by using the same process parameters for all mould types. These parameters were largely dictated by the lower strength SL mould and as such the parameters used for the AL moulding in this work differ to those that may be used in 


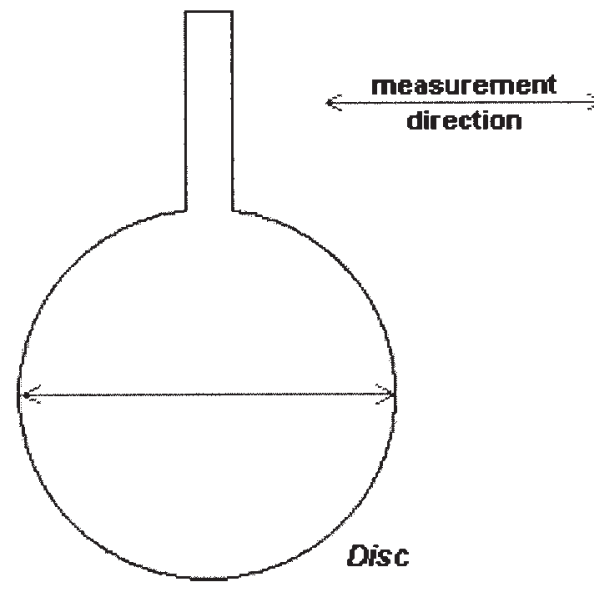

(1) Bar

2 Illustrations of gauge length

a practical case. The important injection moulding parameters were:

(i) Melt temperature set at $270^{\circ} \mathrm{C}$ in each of the five barrel temperature zones.

(ii) Injection speed set at $100 \mathrm{~mm} \mathrm{~s}^{-1}$.

(iii) Injection pressure of 150 bar.

(iv) Follow-up pressure of 150 bar, held for $3 \mathrm{~s}$, on a $100 \mathrm{~mm}$ cushion.

(v) The ambient temperature of the mould before injection was $23.5^{\circ} \mathrm{C}$ with no temperature control system utilised.

(vi) A cooling time of $40 \mathrm{~s}$ before part removal. This was established as the time at which parts could be removed without distortion.

(vii) A clamping force of 15 tonnes.

The injection moulding machine used was a Battenfeld 600/125 CDC model with a Unilog 4000 control unit.

\section{Shrinkage measurements}

Twenty mouldings were produced from each mould type. The PA66 used was Bergamid A70NAT produced by PolyOne. The ABS used was Lustran Ultra 2373 produced by Bayer. The parts and cavities were measured across their gauge length using a Kennedy $331-1330 \mathrm{~K}$ caliper. Since the gate for the bar mould was centrally placed at the top of the gauge length, two measurements were taken either side of the gate for each part and the cavity. Gauge length measurements for both part and mould geometries are illustrated in Fig. 2. The measurements taken from the specimens were compared to the measurements of the cavities and expressed as a percentage difference of the moulding cavity and the parts in each experimental set after compensation for thermal expansion of the mould.

Compensation for thermal expansion of the moulds was established by calculation and by finite element analysis. Both of the mould materials used expand when heated, albeit by differing amounts. The measurements taken for shrinkage must be compensated for the amount of cavity expansion to establish the true amount of difference between mould and part measurements. An in-depth description of how this compensation was determined can viewed in other published work by the authors. ${ }^{17}$

\section{Results}

The resultant shrinkage values are shown in Table 1 . The results show that much greater shrinkage was experienced by a crystalline polymer (PA66) when moulded in a SL mould compared to those from an AL mould. The shrinkage rate of an amorphous polymer (ABS) was consistent irrespective of the mould variety.

With respect to the direction of shrinkage, both polymers demonstrated very slightly more shrinkage in the polymer flow direction (bar specimen) as opposed to the direction perpendicular to polymer flow (disc specimen). These characteristics are common in injection moulded parts. ${ }^{18}$

\section{Research methodology - Part 2}

Since only the crystalline polymer exhibited shrinkage differences, it was suspected that part anomalies were the result of differing degrees of crystallinity developed in the parts. A heavily dominant factor of the crystallinity developed in injection moulded parts is the rate at which they are cooled from their melt condition. ${ }^{19-22}$ Epoxy and aluminium possess very different heat transfer characteristics (aluminium has a thermal conductivity $\sim 1000$ times that of epoxy) and thus would impose very different rates of part cooling when used as unheated injection mould tools. These theories were examined by evaluating the thermal histories experienced by the parts during moulding, and by quantifying the crystallinity of PA66 parts moulded in AL and SL moulds.

The methodology used for producing the parts for evaluation of thermal history and crystallinity analysis was the same as that described in Part 1.

\section{Thermal history profiles}

The heat transfer rate imposed by each mould type was established by real-time data acquisition during the moulding cycle for each mould material variety. Three ktype thermocouples were inserted evenly along the length of the moulding cavity; these positions are illustrated in Fig. 3. The thermocouples were inserted from the rear of the insert such that the probe tips were situated $0.5 \mathrm{~mm}$ below the cavity surface. The end point of the hole was

Table 1 Shrinkage measurements

\begin{tabular}{|c|c|c|c|c|c|c|c|c|}
\hline \multirow[b]{2}{*}{ Mould type } & \multicolumn{4}{|c|}{ PA66 part measurement } & \multicolumn{4}{|c|}{ ABS part measurement } \\
\hline & AL bar & SL bar & AL disc & SL disc & AL bar & SL bar & AL disc & SL disc \\
\hline $\begin{array}{l}\text { Average \% part/mould } \\
\text { difference including } \\
\text { compensation for } \\
\text { thermal expansion }\end{array}$ & $-1 \cdot 34$ & -2.73 & $-1 \cdot 23$ & -2.61 & -0.77 & -0.77 & -0.75 & -0.76 \\
\hline
\end{tabular}




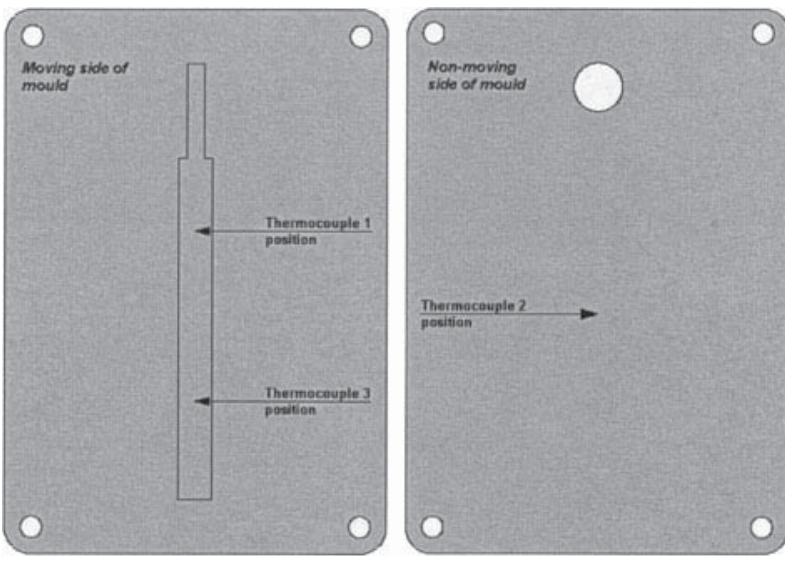

3 Illustration of thermocouple position

created using a ball nosed cutter similar in profile to the welded tip of the thermocouple, this was created to ensure a good contact between the two surfaces without requiring any adhesives. The signals were read and interpreted by an instruNet data acquisition system, then analysed and recorded with a HP VEE software programme. The tool temperature recording system was calibrated in order to verify that the recorded value from the thermocouple was an accurate reflection of the temperature condition at the mould cavity surface. After insertion in the mould, a known temperature was applied to each of the probe positions on the mould cavity surface and a comparison of the recorded temperature from each probe and the actual mould cavity surface temperature was made in respect to their simultaneous values and their response to temperature change. In both cases (SL and AL mould), the difference between the temperatures measured by the thermocouple and the actual surface temperature was never greater than $\pm 1{ }^{\circ} \mathrm{C}$.

Before polymer injection and temperature logging, each mould was at its ambient temperature of $23^{\circ} \mathrm{C}$. The temperature profile was plotted over a period of $10 \mathrm{~min}$.

\section{Crystallinity analysis}

Differential scanning calorimetry (DSC) was used to measure the degree of crystallinity $(\% \chi)$ in the samples. DSC is a thermal analysis technique used to directly measure the temperatures and heat flow to a sample during heating in a controlled atmosphere over a period of time. This technique provides quantitative and qualitative information about physical changes by monitoring endothermic or exothermic processes that represent material transitions. The degree of crystallinity is determined by measuring the energy consumed by the melting of the crystalline areas; this is the heat of fusion. A sample's heat of fusion is proportional to $\% \chi^{23}$ The $\% \chi$ of the sample can be determined by knowing the heat of fusion for the specific sample and ratioing this against the heat of fusion required to melt a completely (100\%) crystallised sample of the material. ${ }^{24}$ Such a value for PA66 is $200 \mathrm{~J} \mathrm{~g}^{-1} 25$

With both these values, it is possible to determine $\% \chi$ by the equation ${ }^{26}$

$$
\% \chi=\Delta H / \Delta H_{100 \%}
$$

where $\% \chi$ is the degree of crystallinity; $\Delta H$ is the heat of

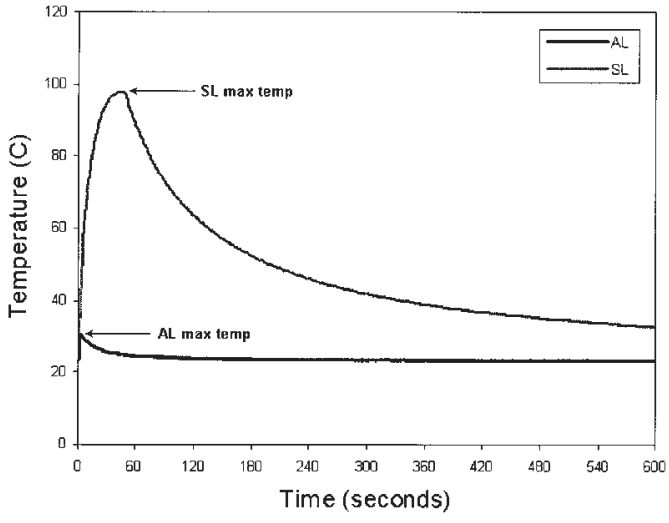

4 Mould temperature profiles including injection and cool down

fusion $\left(\mathrm{J} \mathrm{g}^{-1}\right)$ and $\Delta H_{100 \%}$ is the heat of fusion for $100 \%$ crystallisation.

The sample taken from each of the mouldings was of an average weight of $\sim 17 \mathrm{mg}$. The test samples were taken from a central region of each moulding. A sample was taken from each of four different mouldings from each test specimen variety. The mouldings selected for analysis represented an even distribution of the mouldings which were produced in sequence from each experimental variety. The mouldings examined were numbers $4,8,12$ and 16, from the set of 20 mouldings produced. The apparatus used was a modulated DSC machine produced by TA Instruments, model 2920. The cell atmosphere was provided by a refrigerated nitrogen cooling system produced by TA Instruments.

\section{Thermal history profile - results and discussion}

The thermal history profiles of the bar and disc moulds showed very similar results (within $\pm 5 \%$ ). The average temperature profiles experienced in the moulds during injection and cool down are shown in Fig. 4. The profiles illustrate the vastly different temperature conditions experienced in the SL and AL moulds. The temperature activity in the AL moulds occurred in a very short period of time as a result of the material's high thermal conductivity. The temperature profile in the SL was more extreme and protracted; without external assistance (i.e. cooling by compressed air) the SL mould would take $15 \mathrm{~min}$ to return to its ambient temperature.

\section{Crystallinity analysis - results and discussion}

The DSC results (Table 2) have shown that there was more crystallinity developed in the PA66 parts produced in SL moulds than those produced from AL moulds. The DSC results also showed a slight difference in the curve characteristics displayed by the AL and SL

Table $2 \% \chi$ results

\begin{tabular}{llll}
\hline Sample & Initial & Nucl. agent & Temp. mod. \\
\hline AL 1 & 20.75 & 24.99 & 21.56 \\
AL 2 & 21.84 & 24.29 & 21.05 \\
AL 3 & 21.74 & 24.8 & 21.65 \\
AL 4 & 22.03 & 23.73 & 21.34 \\
SL 1 & 28.42 & 24.97 & $22 \cdot 14$ \\
SL 2 & 27.86 & 24.23 & 22.32 \\
SL 3 & 27.39 & 24.58 & 22.45 \\
SL 4 & 28.15 & 24.31 & 22.31 \\
\hline
\end{tabular}


mouldings. The AL samples demonstrate an exotherm before the heat of fusion, while none of the SL samples showed this in the DSC tests. This exotherm is due to the development of further crystallinity (recrystallisation) during heating in the DSC tests. The absence of any recrystallisation activity in the samples from the SL mould indicates that the level of $\% \chi$ is already at its maximum as a result of its prior conditioning.

The only injection moulding process variable in the experiments was the different cooling rate of the part which is imposed by the heat transfer properties of the mould, as illustrated by the thermal history profiles. It can be deduced that the difference in $\% \chi$ of the parts is because of these different cooling rates.

\section{Research methodology - Part 3}

Since it has been identified that the crystallinity differences in the parts are due to the cooling rate imposed by the inherent heat transfer properties of the mould material, it seems logical that in order to achieve equal crystallinity one should attempt to make these heat transfer characteristics more like those of metal moulds. However, to increase these heat transfer properties by a thousand times, so they are like their aluminium counterpart, is improbable. The limited possible success for tool-based modifications led to a completely different approach that would allow the crystallinity of SL moulded parts to resemble those from metal moulds. This work focuses on another aspect of plastic injection moulding - the material processing element rather than the tooling aspect. This realm of investigation was inspired by the previous DSC analysis which identified the periods of crystal formation and aided in developing an understanding of the morphological activities that occurred during this period. Two such approaches have been taken in this work.

\section{Material based modification}

The first approach concerned the addition of a nucleating agent to the polymer. The development of crystalline structures is related to the speed at which the polymer is cooled from melt. Faster cooling results in a shorter period of time that the polymer spends in the transitional phase of optimum crystal development. This transitional phase is called crystallisation. During this phase, the polymer ceases to be amorphous (molten) and regains its crystalline structure. Crystal growth during this period depends upon the emergence of a central nucleus during crystallisation to begin the growth pattern of a crystal structure, this is known as homogeneous nucleation. It is possible to seed the base polymer with foreign particles that provide preformed nuclei before the crystallisation period by the addition of an additive to the polymer compound known as a nucleating agent. Growth of crystals on such foreign nuclei is known as heterogeneous nucleation. The existence of such independent nuclei allows crystal growth before the formation of natural nuclei by homogeneous nucleation. The presence of heterogeneous nuclei facilitates crystal growth that occurs sooner in the cooling period of the polymer than by homogeneous nucleation. The Nylon used in the previous experiments was available from the same manufacturer with the addition of a nucleating agent

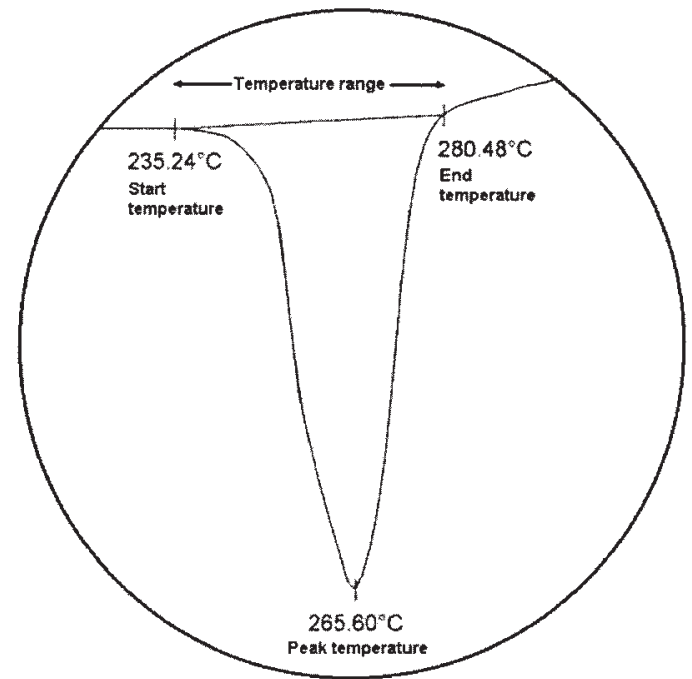

5 Heat of fusion temperature range

and was used in the work described in this section. The material is Bergamid A65S Natural SO manufactured by PolyOne. The procedure for moulding the specimens and morphological analysis was the same as in the previous experiments.

\section{Process based modification}

The second approach to crystallinity control concerned an investigation of altering the injection process parameters. The previous DSC scans identified and quantified the temperature regions in which the development of crystalline content was optimum during cooling of the polymer. This was the temperature range in which the heat of fusion occurred, as shown in Fig. 5. During heating of the polymer, this temperature range also represents the melting phase of the crystalline materials. The melt temperature setting of the injection moulding machine used in all the previous experiments was $270^{\circ} \mathrm{C}$. The DSC work demonstrated that there was a possible temperature range that could be used; this range was $\sim 235-280^{\circ} \mathrm{C}$ (as shown in Fig. 5). This is the critical period where $\% \chi$ was determined during cooling. The greater crystallinity in SL parts was because of a longer time spent in this period of crystal development as a result of the much slower cooling as compared to AL parts. The impetus of this work section was to determine whether setting a lower melt temperature could affect the $\% \chi$ in the part by reducing the amount of time spent in the critical zone of crystal development and thereby reducing the influence of the cooling rate imposed by the mould. Any attempts to influence a part's $\% \chi$ must be effective during the critical temperature range of crystal development (Fig. 5). The range was non-linear and demonstrated a temperature of optimum crystal development. This is the heat of fusion peak shown in the DSC scan. The peak melt temperature in the previous scans occurred at an average temperature of $\sim 266^{\circ} \mathrm{C}$. This indicated the peak period of crystal development occurred $\sim 4^{\circ} \mathrm{C}$ below the polymer melt temperature set by the process in the previous experiments. In an attempt to continue a theme that may provide some correlation with previous tests, the melt temperature in these tests was set $4^{\circ} \mathrm{C}$ below the average peak temperature at $262^{\circ} \mathrm{C}$. This is illustrated in Fig. 6 . The material was Bergamid A70NAT manufactured by 


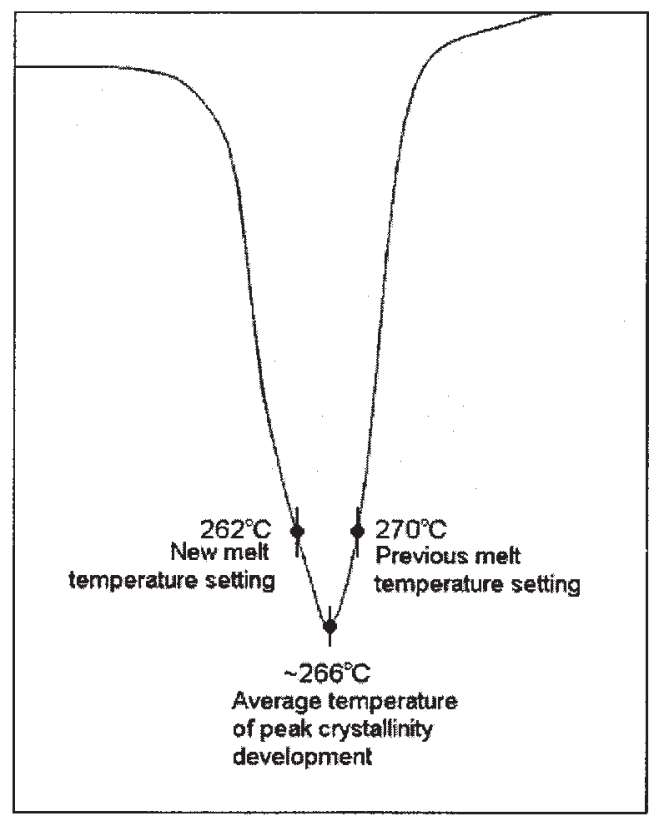

6 Shift in melt temperature settings

PolyOne, the same Nylon as used in the previous experiments in the earlier work. The procedure for moulding the specimens and morphological analysis was the same as in the previous experiments.

\section{Material based modification - results and discussion}

The $\% \chi$ results of the polymer with the addition of a nucleating agent can be seen in Table 2. The results showed that similar values of crystallinity were developed in parts moulded from SL and AL moulds with the addition of a nucleating agent to the PA66. None of the DSC traces showed recrystallisation activity. This indicates that the maximum permissible level of crystallinity existed in all the samples moulded, regardless of whether they were produced in SL or AL moulds. Another characteristic exposed by the DSC scans was the temperature at which peak crystallinity activity occurred. The area of the scan concerned is illustrated in Figs. 2 and 3. A comparison of these results with those from the earlier sections showed that the temperature of peak crystallinity activity was higher. The previous work indicated that maximum crystallisation activity temperatures occurred at $\sim 266^{\circ} \mathrm{C}$; the results of the PA66 with nucleating agent demonstrated that the same peak period occurs consistently at approximately $274^{\circ} \mathrm{C}$. This indicated that crystal activity occurred earlier during the cooling phase compared to PA66 without the addition of a nucleating agent.

\section{Process based modification - results and discussion}

The results from the melt temperature modification can be seen in Table 2. Although not exactly alike, the results showed that, by lowering the melt temperature setting, it was possible to produce parts from the SL moulds which were much more similar in percentage crystallinity to those from the AL moulds compared to previous results. The results indicated percentage crystallinity of the parts from AL moulds was unaffected by melt temperature setting variation. This may indicate that a minimum level of permissible percentage crystallinity was present in the PA66 owing to the extreme rate of rapid cooling in the AL mould. Both sets of results from the different mould types exhibited recrystallisation activity before the heat of fusion, indicating the parts to be of a relative low crystalline content with the development of further crystallinity possible.

\section{Conclusions}

This work has defined that double the amount of shrinkage occurred in PA66 (a crystalline polymer) when injection moulded in an SL tool, compared to an AL tool. Under the same experimental conditions, ABS (an amorphous polymer) demonstrated no such differences. It has been shown that the shrinkage of an amorphous polymer was unaffected by the cooling conditions which were imposed by the mould material type. Consequently, where possible, it is recommended that amorphous polymers are used in preference to crystalline alternatives when using SL moulds.

The establishment of differing part shrinkage in crystalline polymers exposes a flaw in the use of shrinkage compensation factors supplied by manufacturers. This work has shown that the shrinkage of crystalline polymers is dependent upon process conditions which are variable. Supplied shrinkage factors would be specific only to the conditions under which the testpieces were produced. Thus, traditional shrinkage factors are insufficient not only in the use of SL tools, but also any other techniques where there is any significant process variation from the 'norm'.

The experimental work details methods for examination and control of morphology relating to the cooling conditions. The results are applicable not only to SL moulds, but also to other plastic tooling that has poor thermal conductivity. The techniques described in this work could also be applied to cast epoxy tooling.

It has been demonstrated that it is possible to achieve the upper and lower limits of possible crystallinity in a part by applying differing rates of cooling. Such boundaries indicate the possible envelope in which the crystallinity may be varied. The differing extremes of part cooling were caused by the inherent heat transfer properties of the mould materials - AL giving very rapid cooling, and SL producing very slow cooling.

The increased crystallinity of parts caused by the addition of a nucleating agent and melt temperature modification would impact the following properties of the moulded components: ${ }^{24}$

(i) Thermal conductivity (increases with increasing $\% \chi)$.

(ii) Strength and stiffness (increases with increasing $\% \chi)$.

(iii) Impact strength (decreases with increasing $\% \chi$ ).

(iv) Density (increases with increasing $\% \chi$ ).

(v) Transparency (decreases with increasing $\% \chi$ ).

By demonstrating possible control of part crystallinity, this work has demonstrated a possible 'tailoring' of part properties. The process modifications in this work allow different morphology to be realised without changes to the machine, tool or moulded material (i.e. external cooling control, different polymer, etc.). A range of achievable crystallinity would allow certain desirable part properties to be specified. 
The use of a nucleating agent provides parts that are of consistent crystallinity irrespective of the cooling rate. However, the morphology of the parts do not necessarily replicate those produced from a metal tool, and likewise not the same as those produced from plastic tools. The consistent levels of crystallinity are in between those previously experienced in PA66 without nucleating agent from SL and AL moulds. Crystallinity control by melt temperature alteration was indicated by the DSC results that showed a possible range of melt temperature that could be used. As this melting range is the reverse to crystal structure formation, a lowering of the melt temperature allowed a reduction in crystal formation, which resulted in lower crystallinity in the parts from SL moulds. The parts from the AL mould were unaffected by melt temperature variation. Parts from the AL moulds demonstrate low crystallinity as the zone in which crystallinity can be influenced is passed too quickly due to the rapid cooling; the resultant parts achieved the same levels of crystallinity despite melt temperature changes. Thus, this technique has shown itself to be particularly applicable to plastic tooling. This demonstrates a case where the thermal properties of plastic tooling are advantageous. The slow cooling of the part that results from the low thermal conductivity of plastic tooling presents an opportunity for morphology tailoring which was unattainable in metal tooling.

\section{References}

1. P. D. Hilton and P. F. Jacobs: 'Rapid tooling: technologies and industrial applications'; 2000, ISBN 0-8247-8788-9, Marcel Dekker.

2. R. A. Harris and P. M. Dickens: Proceedings of the society of plastics engineers (SPE) annual technical conference (ANTEC), 2001, Dallas, Texas, USA, CRC Press, ISBN 1587160994

3. A. Palmer and J. Colton: Proceedings of the society of plastics engineers (SPE) annual technical conference (ANTEC) 1999, New York, USA, 4002-4006.

4. J. A. McDonald, C. J. Ryall and D. I. Wimpenny: 'Rapid prototyping casebook'; 2001, ISBN 186058076 9, Professional Engineering Publishing.

5. T. Luck, F. Baumann and U. Baraldi: Proc. 4th European RP Conference, Belgriate, Italy, June 1995, 247-260.

6. J. Eschl: European Stereolithography Users Group meeting, Florence, Italy, November 1997.
7. R. A. Harris: Direct AIM tooling. Rapid prototyping \& tooling state of the industry annual worldwide progress report. Wohlers Report 2002, Wohlers Associates Inc, USA, Part 3: Tooling, 70.

8. A. Schulthess, B. Steinmann and M. Hofmann: Proceedings of the 1996 North American Stereolithography Users Group Meeting, San Diego, USA, March 1996.

9. K.-H. Dusel: Society of Manufacturing Engineers Rapid Prototyping and Manufacturing Conference, Dearborn, USA, April 1997.

10. K. Dawson: Proceedings of North American Stereolithography Users Group Meeting, San Antonio USA, March 1998.

11. S. Janyanthi: Stereolithography injection moulds for direct tooling, Proceedings of the 9th European Stereolithography Users Group Meeting, Florence, Italy, November 1997.

12. BS EN ISO 294-1: 'Plastics - injection moulding of test specimens of thermoplastic materials - Part 1: General principles, and moulding of multipurpose and bar test specimens'; 1988, British Standards Institution, Issue 2, ISBN 0580272990

13. BS EN ISO 294 4: 'Plastics - injection moulding of test specimens of thermoplastic materials - Part 4: Determination of moulding shrinkage'; 1988, British Standards Institution, Issue 2, ISBN 0580 278263.

14. ASTM D955: 'Standard test method for measuring shrinkage from mold dimensions of molded plastics'; 1996, American Society for Testing and Materials.

15. R. A. Harris, H. A. Newlyn and P. M. Dickens: J. Eng. Manuf., 2002, IMechE Proc. B, 216, No. B4, ISSN 0954-4054, 499-505.

16. R. A. Harris, N. Hopkinson, H. A. Newlyn, R. J. M. Hague and P. M. Dickens: Int. J Prod. Res., 2002, 40, 719-729.

17. R. A. Harris, R. J. M. Hague, H. A. Newlyn and P. M. Dickens: Int. J. Machine Tools Manuf., 2003, 43, 879-887.

18. A. W. Birley, R. J. Heath and M. J. Scott: 'Plastics materials: properties and applications', 2nd edn; 1988, ISBN 0-216-92489-8, Blackie \& Son Ltd.

19. E. A. Turi: 'Thermal characterization of polymeric materials', 2nd edn; 1997, ISBN 0-12-703783-7, Academic Press.

20. J. A. Brydson: 'Plastics materials', 7th edn; 1999, ISBN 0750641320 , Butterworth-Heinemann.

21. W. Michaeli: 'Plastics processing'; 1995, ISBN 1-56990-144-9, Carl Hanser Verlag.

22. A. W. Birley, B. Haworth and J. Batchelor: 'Physics of plastics: processing, properties and materials engineering'; 1991, ISBN 0-19520918-4, Carl Hanser Verlag.

23. A. E. Woodward: 'Understanding polymer morphology'; 1995, ISBN 1-56990-141-4, Carl Hanser Verlag.

24. G. Hohne, W. Hemminger and H.-J. Flammersheim: 'Differential scanning calorimetry - an introduction for practitioners'; 1996, ISBN 3-540-59012-9, Springer-Verlag.

25. Mettler Toledo: 'Thermoplastics collected applications thermal analysis'; 1998, Switzerland, Mettler Toledo GmbH.

26. G. Potsch and W. Michaeli: 'Injection moulding: an introduction'; 1995, ISBN 1-56990-193-7, Carl Hanser Verlag. 